\title{
A Heparan Sulfate Proteoglycan in Developing Avian Axonal Tracts
}

\author{
Willi Halfter \\ Department of Neurobiology, University of Pittsburgh, Pittsburgh, Pennsylvania 15261
}

\begin{abstract}
A neuronal heparan sulfate proteoglycan was identified by a panel of four monoclonal antibodies. The antibodies were generated from mice immunized with embryonic chick retina basal lamina (clones $3 A 12,3 A 3$, and 9E 10) and embryonic chick optic tract (clone 6D2). Cross-reactivity of all four antibodies with the purified proteoglycan confirmed that the antibodies were directed to the same antigen. Antibodies to heparan sulfate proteoglycan from embryonic chick muscle or EHS mouse tumor (perlecan) did not cross-react with the neuronal heparan sulfate proteoglycan, suggesting that the two proteoglycans are not related. In Western blots, the proteoglycan had a molecular weight of $600 \mathrm{kDa}$ that dropped to $250 \mathrm{kDa}$ when the samples were treated with heparitinase or nitric acid. Immunocytochemistry showed that in early stages of chick and quail development, the proteoglycan was exclusively localized in basal laminae and had a distribution similar to that of laminin. During further development, a strong labeling was also found in the extracellular environment of nerve tracts, such as the optic nerve and white matter areas of the brain and spinal cord. The labeling of axonal tracts declined from embryonic day 10 onward, while labeling in basal laminae persisted. Antibodies to muscle heparan sulfate proteoglycan or to perlecan did not label nerve fibers. The data show that embryonic neuronal tissue expresses a new type of heparan sulfate proteoglycan.

[Key words: extracellular matrix, heparan sulfate proteoglycan, axonal pathways, basal lamina, visual system, chick embryo]
\end{abstract}

Extracellular matrix proteins may provide a supportive or inhibitory environment for growing neurites in the early phase of nervous system development (for recent reviews, see Carbonetto, 1984; Sanes, 1989; Hynes and Lander, 1992). Among the proteins that are supposedly involved in neurite outgrowth are glycoproteins like fibronectin (Baron-van Evercooren et al., 1984), laminin (Smalheiser et al., 1984; Davies et al., 1985; Hopkins et al., 1985; Lander et al., 1985; Cohen et al., 1987; McLoon et al., 1988; Liesi and Silver, 1989), vitronectin (Neugebauer et al., 1991), tenascin (Wehrle and Chiquet, 1990), and thrombospondin (Neugebauer et al., 1991).

Proteoglycans, a special subclass of extracellular matrix proteins, have been detected in the developing nervous system,

\footnotetext{
Received Oct. 21, 1992; revised Jan. 13, 1993; accepted Jan. 25, 1993.

I thank B. Schurer-Halfter for excellent technical help, Dr. M. Vigny for providing me antiserum to EHS mouse heparan sulfate proteoglycan (perlecan), and Dr. J. Yip and R. Perez for critical reading of the manuscript. This work was supported by National Science Foundation Grant BNS-9021 474.

Correspondence should be addressed to Willi Halfter, Department of Neurobiology, University of Pittsburgh, 842 Scaife Hall, Pittsburgh, PA 15261.

Copyright (c) 1993 Society for Neuroscience $0270-6474 / 93 / 132863-11 \$ 05.00 / 0$
}

suggesting that they have a function in the development of axonal pathways as well (Matthew and Patterson, 1983; HantazAmbroise et al., 1987; Dow et al., 1988; Hockfield, 1990). Besides a role in supporting axonal growth, some proteoglycans, such as chondroitin sulfate proteoglycan, may also influence pathfinding of nerve fibers by virtue of a growth inhibitory activity (Verna, 1985; Verna et al., 1989; Snow et al., 1990; Cole and McCabe, 1991; Brittis et al., 1992).

Heparan sulfate proteoglycans (for review, see Gallagher et al., 1986; Gallagher, 1989) comprise a family of proteoglycans with long and unique carbohydrate chains. They exist as integral membrane proteins such as syndecan (Höök et al., 1984; Rapraeger et al., 1986) or as extracellular matrix proteins in basal laminae and cell surfaces (Hassel et al., 1986; Noonan et al., 1991). Since heparan sulfate proteoglycans are found in hasal laminae, which have been shown to be very supportive substrates for neurite outgrowth (Davies et al., 1987a,b; Halfter et al., 1987; Anderson and Tucker, 1989; Condic and Bentley, 1989), and since isolated heparan sulfate proteoglycan from EHS mouse tumor exhibits a neurite outgrowth-promoting activity in vitro (Hantaz-Ambroise et al., 1987; Dow et al., 1988), this class of proteoglycan supposedly has a supportive function for growing neurites. A positive role is also suggested from the fact that the carbohydrate chains of the heparan sulfate proteoglycan may function as a storage site for neurite outgrowth-promoting growth factors, such as fibroblast growth factor (FGF) (Ruoslahti, 1989; Klagsbrun, 1990). An antibody against a complex of heparan sulfate proteoglycan and laminin (Matthew and Patterson, 1983; Chiu ct al., 1986; Bronner-Frazer and Lallicr, 1988) that inhibits neurite growth in several organ culture systems, and a recent study showing that the enzymatic elimination of the carbohydrate chains of heparan sulfate proteoglycan disturbed the directed growth of CNS and PNS axons in organ culture (Wang and Denburg, 1992) support the notion that heparan sulfate proteoglycans are involved in neurite growth and pathfinding. However, none of the heparan sulfate proteoglycans that so far have been identified were shown to be present in developing axonal pathways.

Here, I describe a panel of four monoclonal antibodies that recognize an embryonic neuronal heparan sulfate proteoglycan. The proteoglycan is present not only in basal laminae but also in axonal pathways during the time of active neurite outgrowth. Several lines of data indicate that this neuronal heparan sulfate proteoglycan is different from that in muscle and EHS tumor.

\section{Materials and Methods}

Monoclonal antibody production

Retinal basal laminae were isolated from embryonic day 10 (E10) chick retinas as described elsewhere (Halfter and von Boxberg, 1992). For immunization, basal laminac of 300 retinas werc suspended in $200 \mu \mathrm{l}$ of $\mathrm{Ca} / \mathrm{Mg}$-free Hanks' solution (CMF), mixed with the same amount 


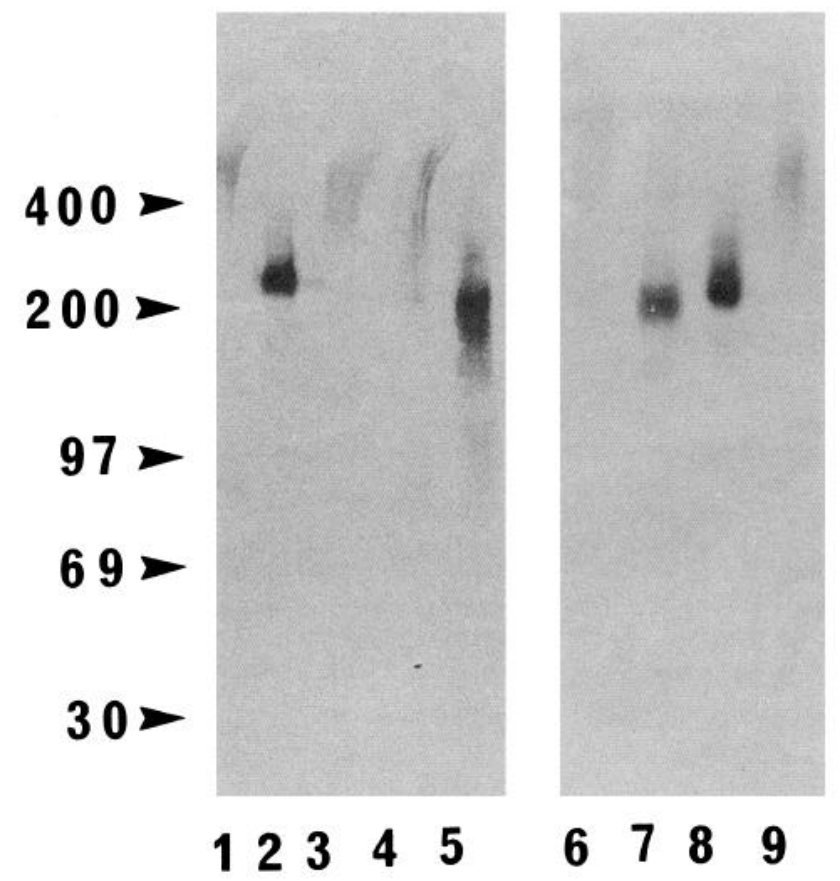

Figure 1. Western blots showing the banding pattern of the neuronal heparan sulfate proteoglycan from chick retinal basal lamina (lanes 1 , 2), vitreous body (lanes 3-7), and optic tract (lanes 8, 9). In lanes 1 and 2, lanes 3-5, and lanes 6-9, respectively, the same amount of protein was loaded. The truncation of the proteoglycan by heparitinase is demonstrated in lanes 2, 5, 7, and 8 . Lanes 1 and 2 are, respectively, control and heparitinase-treated samples from retinal basal lamina. Lanes 3 and 5 are a control and its heparitinase-treated vitreous body sample. Lane 4 shows a sample treated with chondroitinase. Lanes 6 and 7 show samples from vitreous body, and lanes 8 and 9 are samples from optic nerve. Samples in lanes 7 and 8 were treated with heparitinase. The blots were stained with the $3 \mathrm{~A} 12$ monoclonal antibody. The blots show the presence of a heparan sulfate proteoglycan with a core protein of $250 \mathrm{kDa}$ in retina basal lamina, vitreous body, and optic nerve. The core protein of the proteoglycan from vitreous body runs slightly faster on the gel that from basal lamina and optic nerve (compare lanes 2, 8 and 5,7$)$. Note that heparitinase treatment of the sample always results in a stronger staining of the proteoglycan band.

of complete Freund's adjuvant and injected intraperitoneally into Balb/C mice. Boosts were given after 4 and 2 week intervals in incomplete adjuvant. Four days before fusion, a final boost without adjuvant was given. The spleen cells were fused with $\mathrm{X} 63 \mathrm{Ag} 8.653$ myeloma cells (Kearny et al., 1979) as described elsewhere (Fazekas et al., 1980). Hybridoma cells were raised in RPMI medium supplemented with $10 \%$ fetal calf serum and 10\% Origen cloning factor (Igen, Rockville, MD). Wells with clones were screened by immunostaining of sections from E6 chick heads with cell culture supernatants (see below). Positive clones were subcloned twice with the limited dilution method. Four antibodies from two basal laminae fusions were used in this study, $3 \mathrm{~A} 12,3 \mathrm{~A} 3$, and $9 \mathrm{E} 10$ directed against heparan sulfate proteoglycan, and $3 \mathrm{H} 11$ directed against embryonic chick laminin, which was used as a marker for basal laminae and served as a reference for the distribution of the heparan sulfate proteoglycan. The specificity of the $3 \mathrm{H} 11$ for laminin was demonstrated in Western blots showing that the antibody recogized the same peptide bands as a polyclonal anti-EHS laminin antiserum (Bethesda Research Labs, Gaithersburg, MD).

A third fusion was performed with splenocytes from a mouse immunized with optic fiber tracts from E10 chick embryos. To isolate the optic tracts, E10 chick heads were fixed in $4 \%$ paraformaldehyde for 10 min, followed by a second fixation in $70 \%$ ethanol for $3 \mathrm{hr}$. Further dissection was done in $70 \%$ ethanol. After removal of the meninges, the optic tracts were peeled off from the tectal surface with fine needles. Previous studies have shown that the removal of the meninges also removed the pial basal laminae (Kroger and Niehorster, 1990); there- fore, the optic tract preparations did not contain pial basal laminae. Optic tracts were stored in $70 \%$ ethanol. Optic tracts from 25 animals were used per injection. The immunization protocol was identical to the one described above. One antibody from this fusion, 6D2, was used in this study. The antibody was directed against the same heparan sulfate proteoglycan as the $3 \mathrm{~A} 12,3 \mathrm{~A} 3$, and $9 \mathrm{E} 10$ antibodies (see below). The antibodies were all IgGs.

Monoclonal antibodies to embryonic chicken muscle heparan sulfate proteoglycan and chicken tenascin (M1) were obtained from the Developmental Studies Hybridoma Bank (Johns Hopkins University, Baltimore, MD; see Bayne et al., 1984; Chiquet and Fambrough, 1984), and a polyclonal antiserum to EHS mouse tumor heparan sulfate proteoglycan (perlecan) was a generous gift from Dr. M. Vigny (Institute National de la Sante, Paris; see also Vigny et al., 1988). Antisera to EHS laminin and human plasma fibronectin were purchased from Bethesda Research Labs (Gaithersburgh, MD).

\section{Gel electrophoresis and Western blotting}

Chick retina basal laminae, vitreous bodies, or optic tracts were isolated and boiled in sample buffer for $2 \mathrm{~min}$ (Laemmli, 1970). The proteins were separated by $3.6-14 \%$ SDS-PAGE and electrophoretically transferred to nitrocellulose filters (Towbin et al., 1979). After blocking with $5 \%$ skim milk in TBS/Tween (Tris-buffered saline with $0.5 \%$ Tween 20 ), the blots were incubated with the hybridoma supernatants for $1 \mathrm{hr}$. The blots were rinsed three times in TBS/Tween, incubated with 1:5000diluted (TBS/Tween) alkaline phosphatase-conjugated goat anti-mouse IgG (Jackson Laboratories) for $1 \mathrm{hr}$, and finally developed with NBT/ BCIP as described previously (Halfter, 1989). Some samples were pretreated with chondroitinase ABC, hyaluronidase (Boehringer Mannheim, Indianapolis, IN), or heparitinase (Seikagaku, Rockville, MA) for $2 \mathrm{hr}$ at $37^{\circ} \mathrm{C}$ under buffer and $\mathrm{pH}$ conditions recommended by the manufacturers. Other samples were pretreated with nitric acid to cleave the carbohydrates from the heparan sulfate proteoglycan (Soroka and Farquhar, 1991). Enzyme digestions were performed in the presence of $1 \mathrm{~mm}$ phenylmethyl sulfonyl fluoride (Sigma) and $N$-methylmaleimide (Sigma) to limit proteolysis. As a control, some digestions were performed in the presences of excessive heparan sulfate $(100 \mu \mathrm{g} / \mathrm{ml}$ final concentration; Sigma). The pretreated samples were then boiled in sample buffer as described above.

\section{Antigen isolation}

Ascites from the $3 \mathrm{~A} 12$ and the $6 \mathrm{D} 2$ clones were obtained by injection of the tumor cells into the peritoneal cavities of $\mathrm{Balb} / \mathrm{C}$ mice. The IgGs from the $3 A 12$ and $6 D 2$ ascites were isolated over a DEAE AffiGel Blue (Bio-Rad, Melville, NY) column and coupled to cyanogenbromideactivated sepharose 4B (Pharmacia, Piscataway, NJ) according to the manufacturers procedure. The $3 \mathrm{~A} 12 / 6 \mathrm{D} 2$ antigen was isolated from $\mathrm{E} 10$ chicken vitreous bodies by immunoaffinity purification. The vitreous bodies from 400-1000 eyes were collected and spun down at 10,000 $\mathrm{rpm}$ for $10 \mathrm{~min}$. The supernatant $(20-50 \mathrm{ml})$ was incubated with the $3 \mathrm{~A} 12$ sepharose overnight. After extensive washing of the sepharose with $100 \mathrm{ml}$ each of $0.5 \% \mathrm{TBS} / \mathrm{T}$ ween, $0.5 \% \mathrm{TBS} /$ deoxycholate, and TBS alone, the antigen was eluted with $0.1 \mathrm{M}$ diethylamine/acetic acid buffer ( $\mathrm{pH} 11.5)$. Fractions were tested by gel electrophoresis and antigen-containing fractions were collected, lyophilized, and taken up in $1 / 10$ th of the original volume in CMF. The concentration of the proteoglycan was estimated both by the dye-binding method of Minamide and Bamburg (1990) and by gel electrophoresis. The isolated proteins were separated by SDS-PAGE, and the protein bands were detected by staining the gels with colloidal brilliant blue G (Sigma) overnight. The concentration of the samples was estimated by comparing the staining density of the proteoglycan band with that of known concentrations of laminin and fibronectin (Bethesda Research Labs) in adjacent lanes of the gel (see Fig. 3, lanes 1-3). Each purification yielded between 2 and $5 \mu \mathrm{g}$ of proteoglycan.

\section{Histology}

Light microscopy. Heads from E3-E14 chick embryos were fixed in 4\% paraformaldehyde in $0.1 \mathrm{M}$ potassium phosphate buffer $(\mathrm{pH} 7.4)$ for 1 hr. The specimens were washed in CMF and cryoprotected with $30 \%$ sucrose for $4 \mathrm{hr}$. The heads were sectioned after embedding and mounting in O.C.T. compound (Miles, Elkhart, IN) with a Reichert Jung (Nussloch, Germany) cryostat at $25 \mu \mathrm{m}$. Sections were mounted on gelatin/chrome alum-subbed slides and incubated with supernatants 

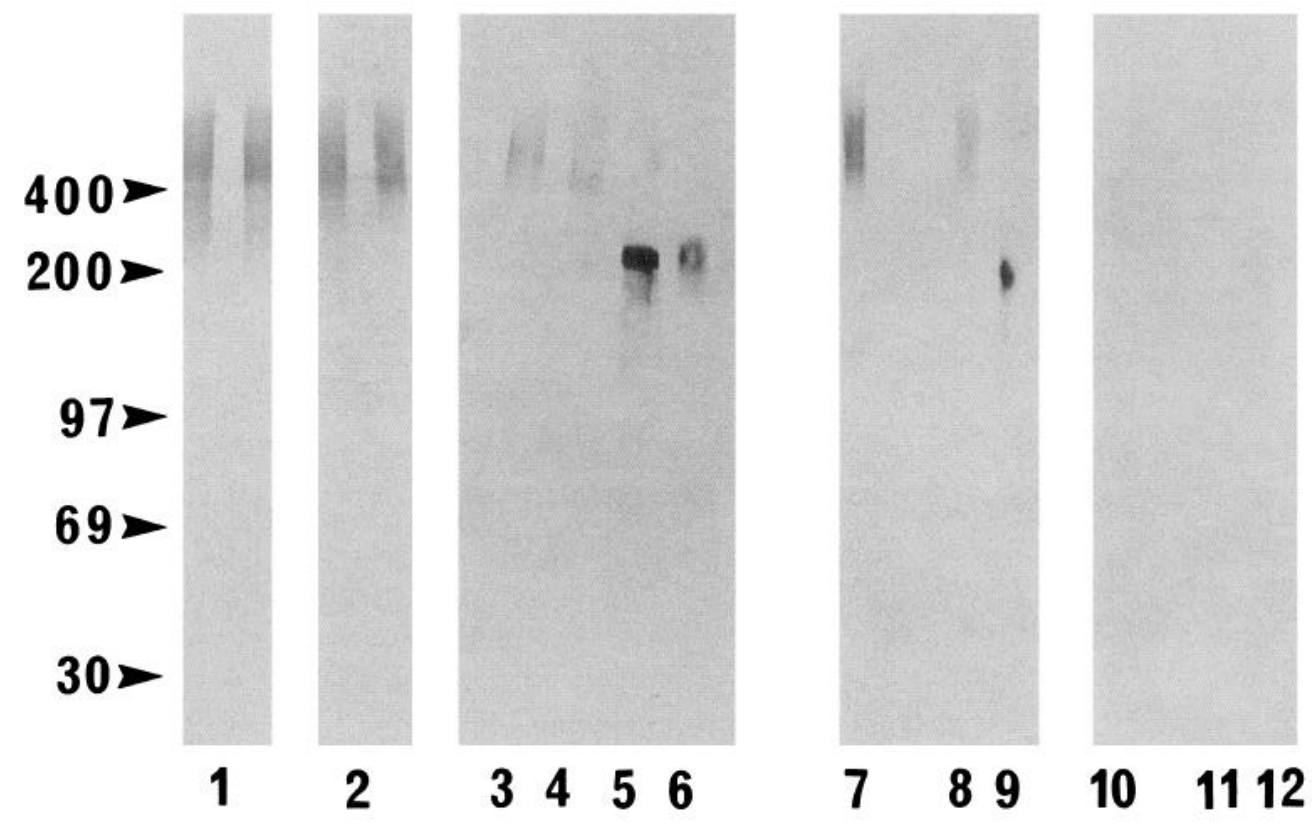

Figure 2. Cross-reactivity of the $3 \mathrm{~A} 12$ antigen with the 6D2 antibody (lanes 2-9), and lack of cross-reactivity of the $3 \mathrm{~A} 12$ antigen with the polyclonal antiserum to perlecan (lanes 10-12). The 3A12 antigen was isolated by affinity chromatography. On Western blots, the proteoglycan is recognized by both the $3 \mathrm{~A} 12$ (lane 1) and the 6D2 (lane 2) antibodies. The $3 \mathrm{~A} 12$ antigen is truncated by heparitinase (lane 5 ) and nitric acid (lane 6) to a narrow band of $250 \mathrm{kDa}$. When the heparitinase treatment was performed in the presence of heparan sulfate (lane 4), the molecular weight stays the same as in the control (lane 3). The $3 \mathrm{~A} 12$ antigen is not recognized by the antiserum to perlecan, as demonstrated by a side-by-side comparison of blots reacted with the 6D2 antibody (lanes 7-9) and the perlecan antiserum (lanes 10-12). The samples in all lanes are 3A12 antigen loaded at the same concentration. Lanes 7 and 10 are the nonreduced, lanes 8 and 11 are the reduced $3 \mathrm{~A} 12$ antigen, and lane 9 and 12 are the heparitinase-treated and reduced $3 \mathrm{~A} 12$ antigen.

from the myeloma cell cultures for $1 \mathrm{hr}$. After three rinses, the sections were incubated with a fluorophor-labeled secondary antibody for another hour. As secondary antibodies, affinity-purified goat anti-mouse antibodies labeled with FITC or Cy-3 were used (Jackson ImmunoResearch, West Grove, PA). After two final rinses, the specimens were examined with an epifluorescence microscope (Zeiss, Thornwood, NY).

For the localization of the antigen in neural tissue of live embryos, eyes of E6 and E7 embryos were injected with the ascites fluid $(2 \mu \mathrm{l} /$ eye) of the 6D2 clone. After $24 \mathrm{hr}$, the heads of the embryos were fixed and cryosectioned as described above. The distribution of the injected antibody was visualized by reacting the sections with secondary antibody as described above. Injection of antibodies into live tissue labels extracellular antigens only. Control injections with antibodies to intracellular antigens like actin or tubulin did not result in any staining of the retina (Halfter and Chen, 1987). Further, injection of ascites from myeloma cells secreting antibodies against other extracellular proteins, such as tenascin, resulted in entirely different distribution patterns.

Electron microscopy. Ascites from the 6D2 clone was injected into the eyes of E6 or E7 chick embryos in ovo as described above. After 24 $\mathrm{hr}$, the retinas of the injected eyes were dissected out and mounted onto membrane filters (Halfter and Chen, 1987). The retina filter assemblies were incubated in peroxidase-labeled goat anti-mouse (Fab $)_{2}$ fragments (Jackson, West Grove, PA) in Dulbecco's modified Eagle's medium/ $10 \%$ fetal calf serum for $2 \mathrm{hr}$ at a dilution of $1: 100$. The retinas were fixed in $0.5 \%$ glutaraldehyde for $10 \mathrm{~min}$ and reacted with diaminobenzidine $/ \mathrm{H}_{2} \mathrm{O}_{2}$. After $15 \mathrm{~min}$ the reaction was stopped by rinsing in CMF and fixation of the preparation in $2.5 \%$ glutaraldehyde in $0.1 \mathrm{M}$ cacodylate buffer ( $\mathrm{pH} 7.4$ ). Following osmication, the specimens were embedded in Epon and thin sectioned according to standard procedures.

For immunostaining of neurites grown in tissue culture, explants from dorsal root ganglia or retina were cultured on laminin (Bethesda Research Labs)-coated dishes (Halfter, 1989), fixed in 4\% paraformaldehyde for $5 \mathrm{~min}$ as described above, and stained with the $3 \mathrm{~A} 12$ or $6 \mathrm{D} 2$ antibodies, followed by Cy3-labeled secondary antibody.

\section{Results}

Monoclonal antibodies to proteins from basal laminae and optic pathway were generated by immunizing two mice with embry- onic chick retina inner limiting membranes and one mouse with optic tract. The immunized animals mounted a strong response to the immunogens, demonstrated by the fact that serum samples from the mice, diluted up to $1: 20,000$, specifically labeled basal laminae or nerve fiber tracts in tissue sections. Among the hybridomas isolated, three clones (3A12, 3A3, and 9E10) from the basal laminae fusions and one (6D2) from the optic tract fusion were collected for further studies. In sections, the antibodies showed a strong labeling of basal laminae zones, such as the subepidermal region, the kidney glomeruli basal laminae (not shown), the pial surface of the brain, and the basal surface of neural epithelia. In addition, the antibodies strongly labeled the developing nerve fiber layers (see below).

\section{Western blot analysis and immunopurification}

In Western blots using basal laminae as a sample, the $3 \mathrm{~A} 12$, $3 \mathrm{~A} 3,9 \mathrm{E} 10$, and 6D2 antibodies labeled a diffuse band with a molecular weight of approximtely $600 \mathrm{kDa}$ (Fig. 1, lane 1). Upon treatment of the samples with heparitinase, the smear at 600 $\mathrm{kDa}$ dropped to a narrow band with a molecular weight of 250 $\mathrm{kDa}$ (Fig. 1, lane 2). The treatment with heparitinase resulted in a stronger signal on the blot, indicating that the antibodies recognized the core protein of the proteoglycan. Chondroitinase (Fig. 1, lane 4) and collagenase (not shown) treatment of the samples caused no shift in molecular weight. Analysis of other parts of the chick embryo showed that the proteoglycan was detectable in the vitreous body (Fig. 1, lanes 3, 5) and in optic nerve (Fig. 1, lanes 8,9 ), but not in serum and cerebrospinal fluid (not shown). In optic tracts, the molecular weights of the intact and the heparitinase-treated proteoglycans were identical to those from basal laminae (Fig. 1, lanes 8,9). In vitreous body, however, the core protein ran slightly faster than the core protein 


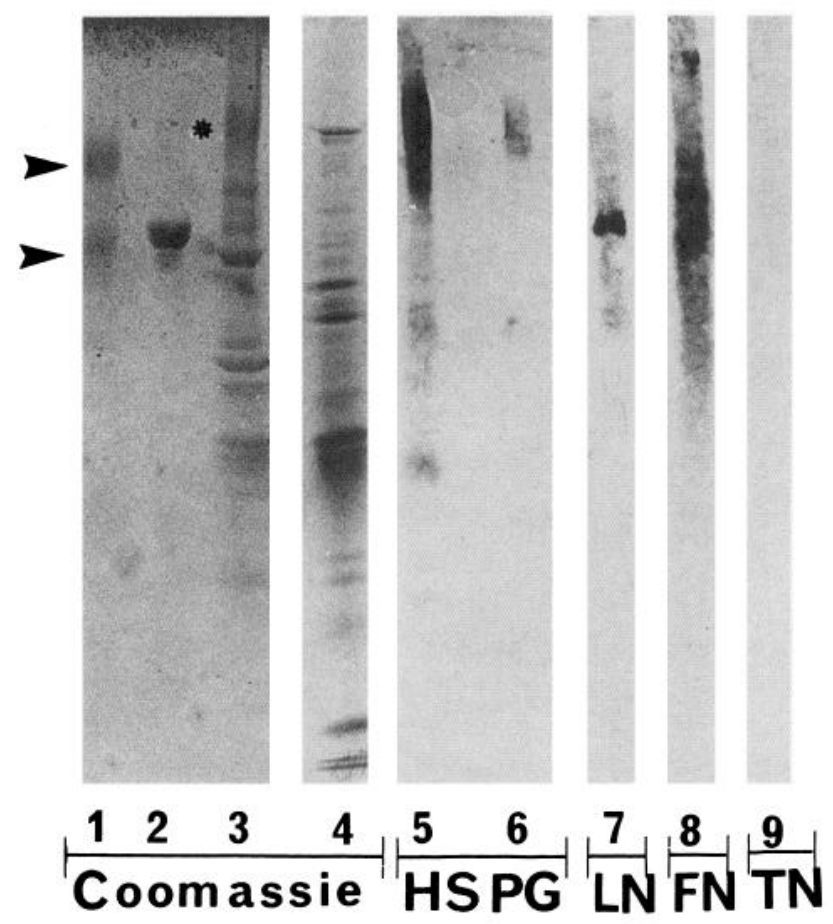

Figure 3. The affinity-purified neuronal heparan sulfate proteoglycan enriches several other vitreous body proteins, as shown by Coomassie staining (lane 1-3) and Western blotting (lanes 5-9). When 3-4 $\mu \mathrm{g}$ of affinity purified $3 \mathrm{~A} 12$ antigen was separated by SDS-PAGE, at least 10 protein bands were detected (lane 3 ). The location of the heparan sulfate proteoglycan band in the gel is indicated by the asterisk. The amount of proteoglycan relative to their other protein bands is underrepresented, since the proteoglycan does not stain well with Coomassie. Laminin (4 $\mu \mathrm{g}$; lane 1 ) and fibronectin (lane 2) were loaded on adjacent lanes of the gel. The protein banding pattern of the vitreous body proteins is shown in lane 4 . Note that the banding patterns in lanes 3 and 4 were different. Western blots from the same gel, loaded with only $1 / 10$ th the amount of protein and stained with the 6D2 antibody, localize the heparan sulfate proteoglycan (HSPG) smear at $600 \mathrm{kDa}$ (lane 5). The normal concentration of the proteoglycan in vitreous body is shown in lane 6, for comparison. The presence of laminin $(L N)$ and fibronectin $(F N)$ in the sample is shown in lanes 7 and 8 . Tenascin $(T N)$ was not dectectable (lane 9). The arrowheads indicate the level of 400 and $200 \mathrm{kDa}$ in the gel.

of the proteoglycan from basal lamina and optic nerve (compare lanes 2, 8 and 5, 7 in Fig. 1).

Evidence that the four antibodies recognized the same antigen came from cross-reactivity experiments. The antigen was purified from vitreous body by immunoaffinity chromatography using the $3 \mathrm{~A} 12$ or $6 \mathrm{D} 2$ antibodies immobilized to sepharose. The isolated proteoglycan was recognized by all four antibodies as exemplified in Figure 2 (lanes 1,2). For example, the 6D2 antibody labeled the $3 \mathrm{~A} 12$ antigen as a smear at $600 \mathrm{kDa}$ that dropped to a band around $250 \mathrm{kDa}$ after treatment with heparitinase (Fig. 2, lane 5). Treatment of the sample with nitric acid, which specifically cleaves the carbohydrate chains from heparan sulfate proteoglycans, reduced the smear at $600 \mathrm{kDa}$ to a narrow band at $250 \mathrm{kDa}$ (Fig. 2, lane 6), identical to the banding pattern obtained after heparitinase treatment.

The only difference between the different antibody clones was their reactivity to reduced and nonreduced samples. Whereas the $3 \mathrm{~A} 12,3 \mathrm{~A} 3$, and $9 \mathrm{E} 10$ antibodies did not label bands in Western blots when the sample was reduced with mercaptoetha- nol, the 6D2 antibody did. Using the 6D2 antibody, it was found that the molecular weights of the proteoglycan and its core protein were not changed by reduction of their disulfide bonds (Fig. 2, lanes 8,9).

Cross-reactivity studies also showed that the neuronal heparan sulfate proteoglycan was not recognized by antibodies to muscle or mouse tumor heparan sulfate proteoglycan (perlecan). Both a monoclonal antibody to embryonic chick muscle heparan sulfate proteoglycan (33-2) and a polyclonal antiserum to perlecan did not cross-react with the intact, reduced, or heparitinase-treated neuronal heparan sulfate proteoglycan (Fig. 2, lanes 10-12).

When microgram quantities of the isolated antigen were loaded on the gels, it was found that the isolated heparan sulfate proteoglycan was contaminated by several other proteins (Fig. 3 , lane 3 ). The banding pattern of these proteins did not match the banding pattern of the vitreous body proteins (Fig. 3, compare lanes 3,4 ), suggesting an enrichment of a subpopulation of the vitreous body proteins together with the heparan sulfate proteoglycan. Western blotting showed that heparin-binding proteins, such as laminin (Fig. 3, lane 7) and fibronectin (Fig. 3 , lane 8 ), were enriched whereas major components of vitreous body, such as tenascin (Fig. 3, lane 9) and serum albumin (not shown), were not present in the sample. A nonspecific binding of proteins to a particular antibody after immobilization or to the sepharose matrix was excluded, since immunopurification of heparan sulfate proteoglycan with immobilized 3A1 2 or 6D2 IgG yielded the same banding patterns, and immunoaffinity purification of chondroitin sulfate proteoglycan from vitreous body with two other antibodies yielded a clean proteoglycan without any contaminations (C. Ring and W. Halfter, unpublished observations).

\section{The distribution of the neuronal heparan sulfate proteoglycan}

The distribution of the $3 \mathrm{~A} 12$ antigen in the developing optic system of the chick was investigated in detail. From the earliest stages of eye development (E2), the antigen appeared in the basal lamina of the retina, the pigment epithelium and in the surface of the lens (Fig. $4 a, c$ ). With regard to basal laminae, the staining pattern of the neuronal heparan sulfate proteoglycan was similar to the labeling obtained with an antibody to laminin (Fig. 4b,d). In the lens, however, the $3 \mathrm{~A} 12,3 \mathrm{~A} 3$, and $9 \mathrm{E} 10$ antibodies stained the lens less intensely than did the laminin antibody, and from E6 onward, the heparan sulfate proteoglycan was no longer detectable in the lens basal lamina (Fig. 4e).

By E4, the heparan sulfate proteoglycan was first detectable in the developing optic nerve (arrow in Fig. 4c). A prominent labeling in the optic pathway of the retina was observed from E5 onward. The staininig of retinal axons continued into the optic stalk (Fig. $5 a$ ), the surfaces of the brain stem, and tectum opticum (Fig. 6a).

The heparan sulfate proteoglycan was found not only in the developing optic nerve, but also in many other afferent and efferent fiber tracts of the chick CNS and PNS. Staining was found in the supraoptic commissure (not shown), the tectobulbar tract (Fig. $6 a$ ), the presumptive white matter of the spinal cord, and the dorsal root ganglia (not shown). Labeling of fiber tracts was prominent up to E10, but declined thereafter. Staining of optic axons, for example, decreased by E9, and by E12 little labeling of axons was seen in the retina, optic nerve, and tectum. During the same time period, the staining of basal laminae 

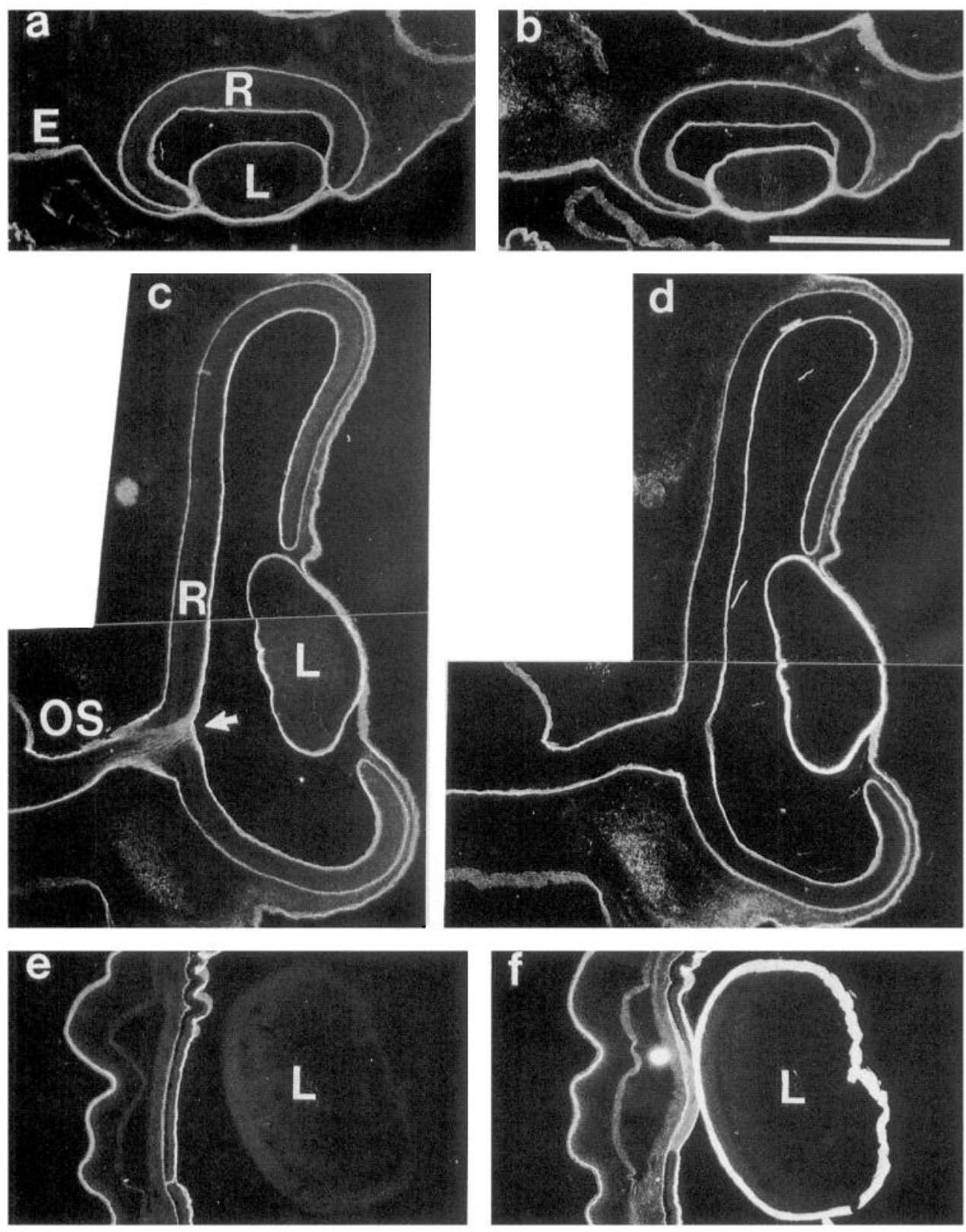

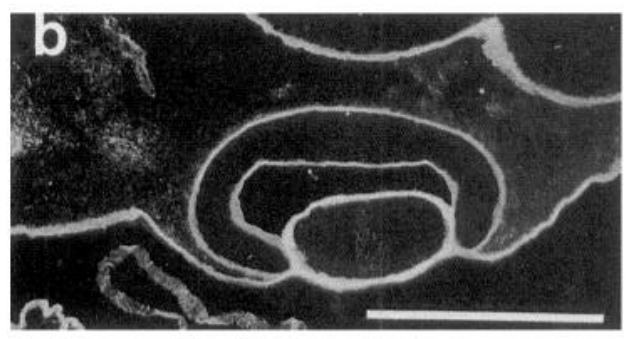

Figure 4. Immunofluorescence micrographs showing the distribution of the $3 \mathrm{~A} 12$ antigen in the embryonic chick eye at E2 $(a), \mathrm{E} 4(c)$, and E6 $(e)$. In the adjacent sections, the distribution of laminin is shown as a reference $(b, d$, $f)$. At $\mathrm{E} 2$ and $\mathrm{E} 4$, the $3 \mathrm{~A} 12$ antigen is abundant in the basal laminae of retina $(R)$, lens $(L)$, and epidermis $(E)$. By E4, the optic fibers in the optic stalk $(O S$; arrow in $c$ ) are labeled with the antibody. By E6, the proteoglycan is no longer detectable in the lens capsule (compare $e$ and $f$ ). Scale bar, $250 \mu \mathrm{m}$. remained prominent (Fig. $5 c$ ). Further, it was only by E10 that a significant labeling of blood vessels and muscle fibers became apparent (Fig. 5c).

Support for the existence of the $3 \mathrm{~A} 12,3 \mathrm{~A} 3$, and $9 \mathrm{E} 10$ antigens in developing nerve fiber layers came from the finding that an antibody from a fusion against optic tract antigens also recognized the neuronal heparan sulfate proteoglycan. The 6D2 antibody labeled basal laminae and fiber tracts exactly like the $3 \mathrm{~A} 12,3 \mathrm{~A} 3$, and 9E10 antibodies had. In early development, the 6D2 antibody stained exclusively basal laminae (Fig. 7a). The early staining of the lens capsule disappeared by E6, and a strong labeling of fiber tracts in the retina, brain, and spinal cord appeared from E4 onward (Fig. 7b-d). By E9/E10, the 6D2 labeling disappeared from the retinal optic fiber tract and was found in basal lamina structures only (Fig. 7e).
Immunostaining of cell-free basal lamina whole-mounts was performed to see whether the antigen was localized in the extracellular environment. Flat-mounted retinal basal laminae, which were extracted with detergent to remove all cellular components (Halfter et al., 1987), showed a strong labeling, indicating that the antigen resides in the extracellular matrix (Fig. $8 a)$.

In vivo injections of the antibody into the eyes of live embryos were performed to demonstrate the presence of the antigen on the surface of optic axons. By both immunofluorescence microscopy (Fig. $8 b$ ) and electron microscopy (Fig. $8 d$ ), the proteoglycan could be detected in the inner limiting membrane, the optic fiber layer, and the inner plexiform layer of the retina (Fig. $8 b, d)$. At the ultrastructural level, the proteoglycan was found in the inner limiting membrane and on the surface of the in- 

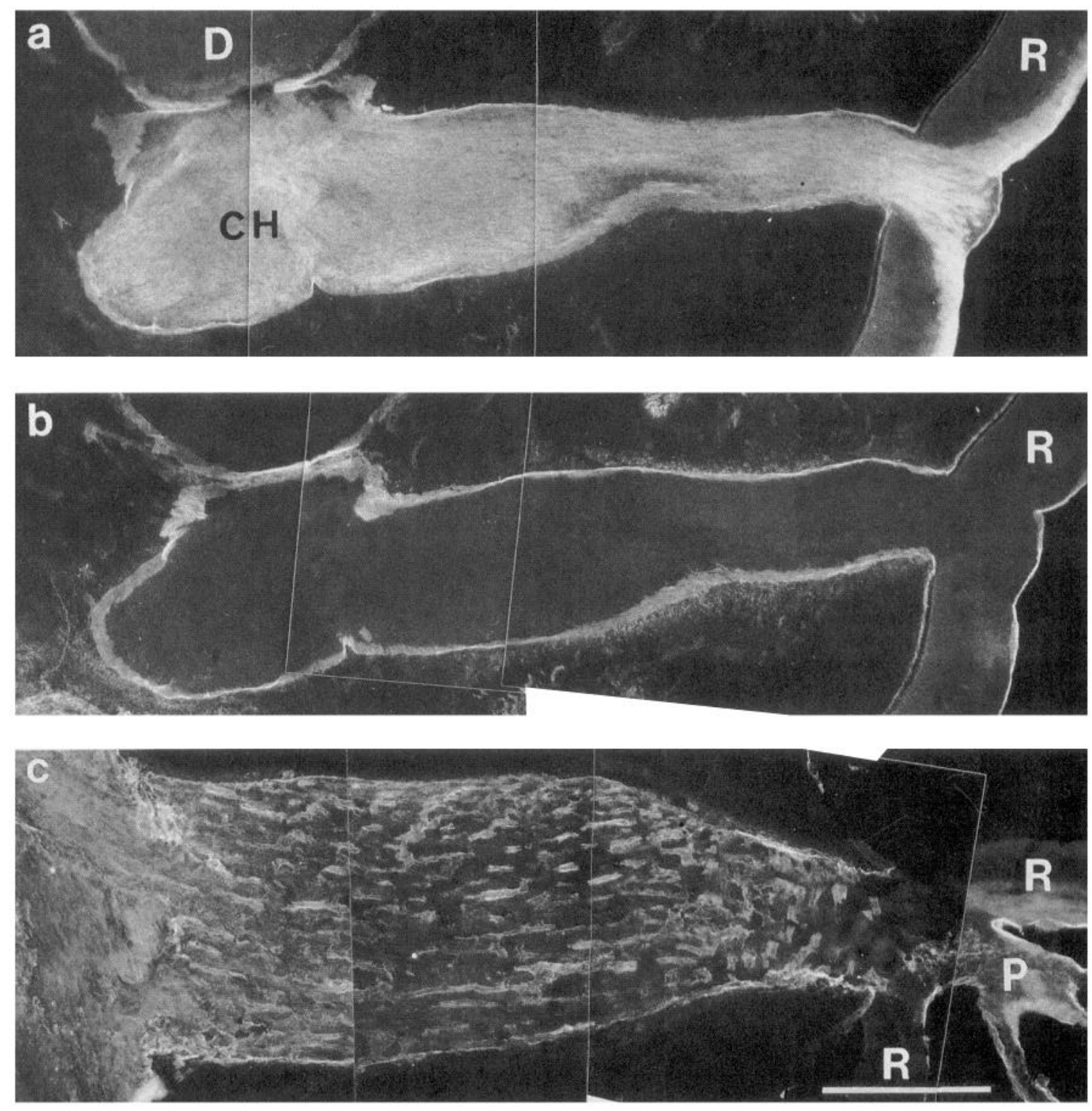

Figure 5. Immunofluorescence staining of the 3A12 antigen in the developing optic nerve. At E6, the basal laminae as well as the nerve fibers in the retina $(R)$, optic nerve, and chiasma $(\mathrm{CH} ; \mathrm{a} ; \mathrm{D}$, diencephalon) were strongly labeled. An adjacent section labeled with anti-laminin antibody showed that laminin is confined to the basal laminae of the retina and optic nerve $(b)$. At a late stage of optic pathway development (E12; $c$ ), the $3 \mathrm{~A} 12$ antigen has disappeared from the nerve fibers and is only detectable in basal laminae. The labeling inside the optic nerve corresponds to the basal laminae of the blood vessels. $P$, pecten. Scale bar, $250 \mu \mathrm{m}$.

dividual axons in the optic fiber layer (Fig. 8d). Axons grown in tissue culture did not express the proteoglycan. When retinal or dorsal root ganglia neurites, grown in vitro, were stained with the $3 \mathrm{~A} 12$ or $6 \mathrm{D} 2$ antibodies, no staining was observed, indicating that the antigen was not present on axons grown in culture (not shown).

\section{The distribution of the muscle and EHS heparan sulfate proteoglycan (perlecan)}

The distribution of the neuronal heparan sulfate proteoglycan was compared with that of the already characterized heparan sulfate proteoglycans from muscle and EHS mouse tumor. Sections from chick embryos were stained with a monoclonal antibody to heparan sulfate proteoglycan from embryonic chick muscle (33-2; Bayne et al., 1984). By E5, the most prominent labeling with this antibody was observed in the basal lamina of the lens (not shown). A weak staining was found in the inner limiting membrane of the retina and the pial surface of the brain (Fig. 9b,d). With further development (E10), the basal laminae of the muscle fibers became prominently labeled (Fig. $9 f$ ). A side-by-side comparison of the distribution of the muscle and neuronal heparan sulfate proteoglycans (Fig. 9) showed that the muscle proteoglycan was absent or very weakly represented in areas where the neuronal type was prominent (inner limiting membrane of the retina, axonal tracts, pia, blood vessels). On the other hand, the muscle heparan sulfate proteoglycan was prominent in areas where the neuronal proteoglycan was scarce (lens, muscle fibers). At no stage and at no place in the embryo did the anti-muscle heparan sulfate proteoglycan antibody stain axonal tracts (Fig. 9b,d,f). A polyclonal antiserum to the high- 

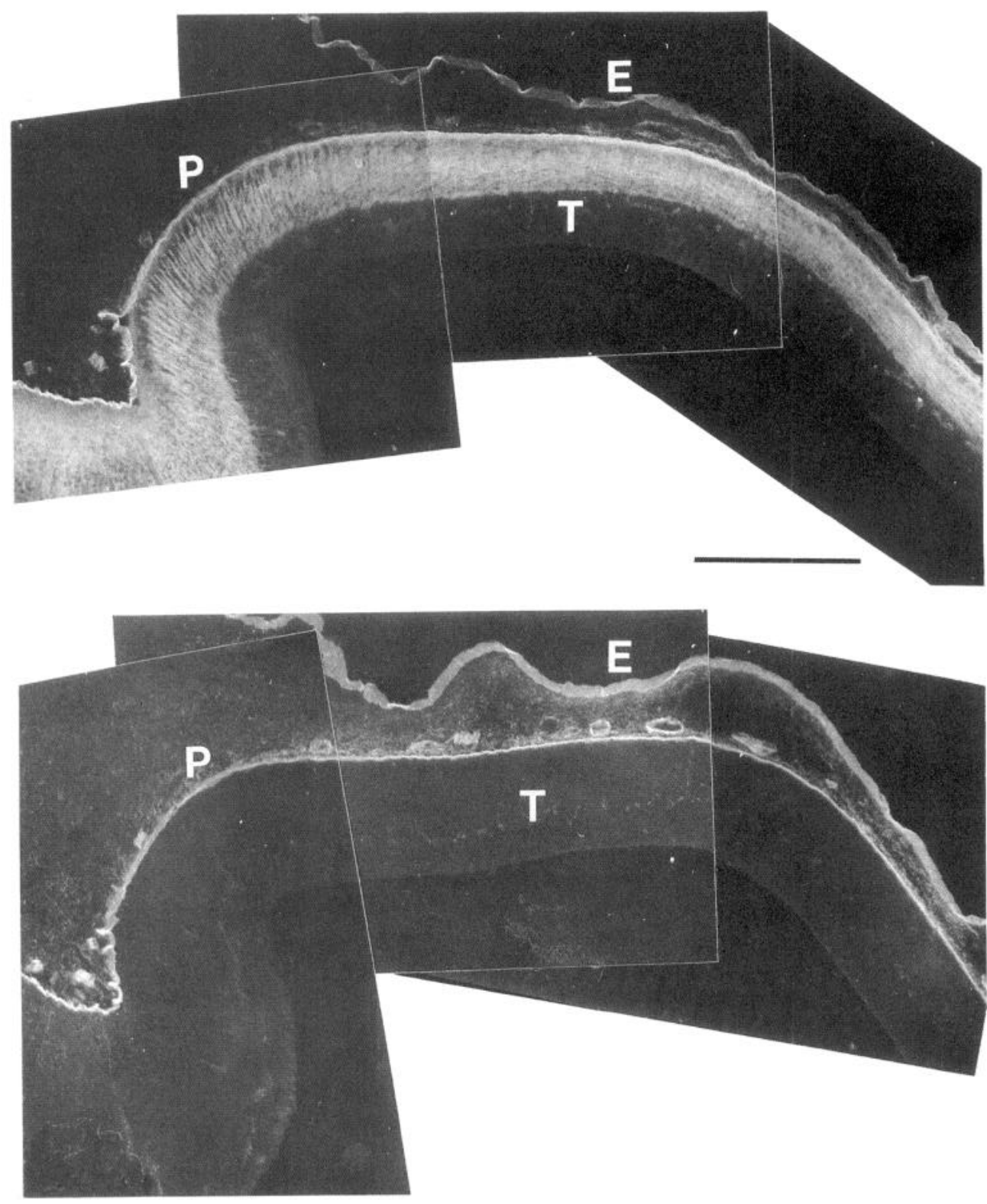

Figure 6. Immunofluorescence staining of the E6 chick optic tectum ( $T$ ) showing the presence of the $3 \mathrm{~A} 12$ antigen in the developing tectobulbar pathway $(a)$. In addition to the basal laminae ( $P$, pia; $E$, epidermis), the early axons of the tectobulbar pathway are labeled with the $3 \mathrm{~A} 12$ antibody. As a reference, the staining with laminin antibody on the adjacent section is shown in $b$. Scale bar, $250 \mu \mathrm{m}$. molecular-weight heparan sulfate proteoglycan perlecan (Vigny et al., 1988) was also used for labeling sections from embryonic chick tissue. Its staining pattern was identical to that of the 33-2 monoclonal antibody (not shown).

\section{Discussion}

Using basal laminae and optic tracts as immunogens, four monoclonal antibodies were obtained that labeled both basal laminae and developing nerve fiber pathways. Immunocytochemistry, Western blotting, and cross-reactivity experiments demonstrate that the four antibodies recognized a novel type of heparan sulfate proteoglycan.

The presence of the basal laminae proteoglycan in axonal pathways was shown by the strong labeling of developing axonal tracts, such as the visual pathway, the tectobulbar pathway, the supraoptic commissure, and the presumptive white matter area of the spinal cord. The immunocytochemical studies were confirmed by Western blots showing the presence of the heparan sulfate proteoglycan in developing optic tract, basal laminae, and vitreous body. Since the antibodies were obtained from several independent fusions using both basal laminae and optic tracts as immunogens, it is likely that the proteoglycan is not a rare, but a prominent component of the brain extracellular matrix.

In the earliest stages of optic pathway development, the heparan sulfate proteoglycan was present in basal laminae only. The proteoglycan was detectable in fiber tracts only when a significant number of axons had been generated. Thus, the protein does not occur in axonal pathways prior to the arrival of nerve fibers, but rather emerges together with the ingrowing nerve fibers. Regarding the origin of the proteoglycan in nerve fiber tracts, the proteoglycan could have been (1) synthesized by nerve cells and expressed on the axonal surface, (2) secreted by the ventricular cells and bound by receptors on the axonal surface, or (3) originated from both nerve cells and ventricular cells. Secretion of the proteoglycan by the ventricular cells is likely, since the protein is deposited in the basal lamina matrix prior 

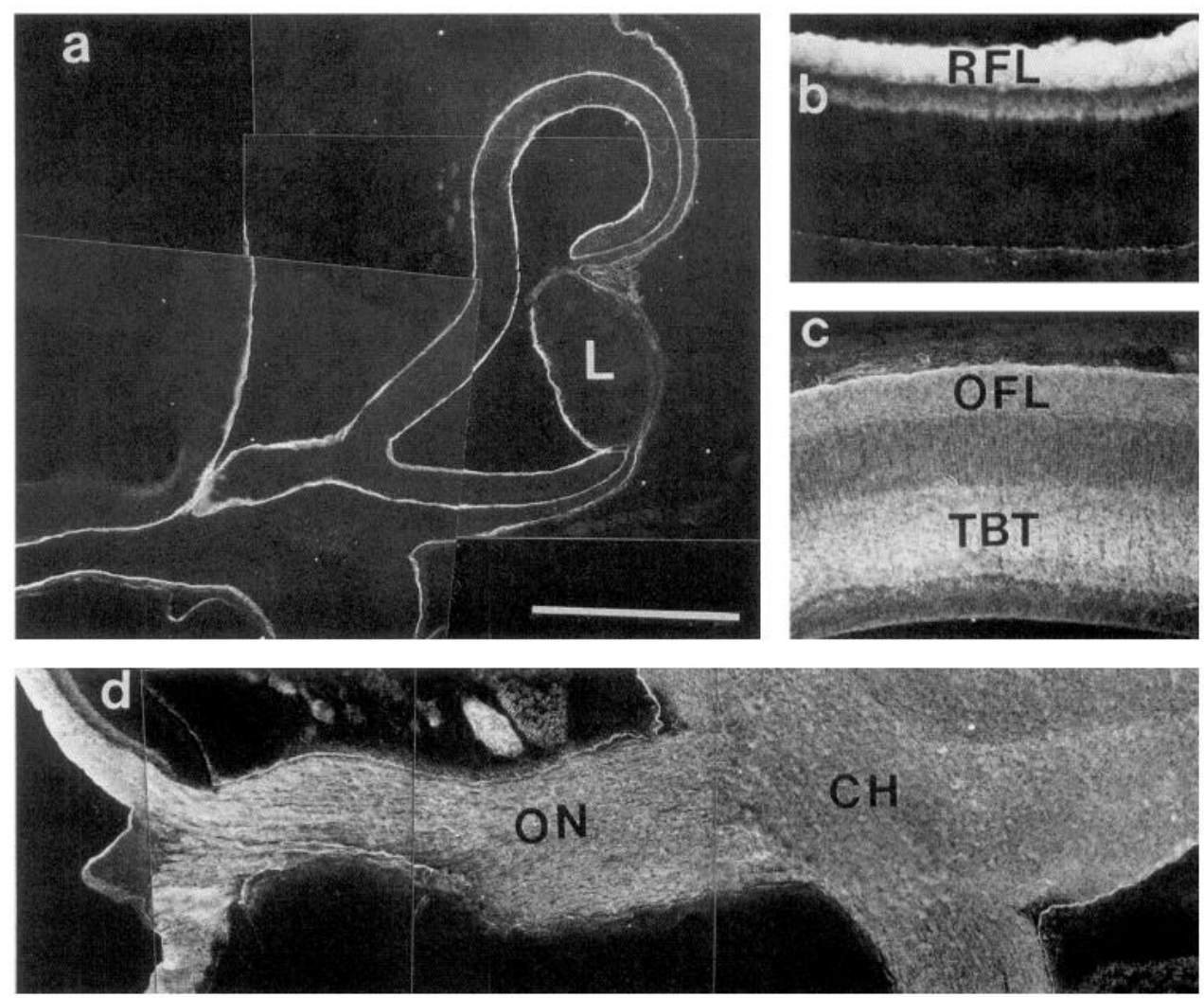

Immunofluorescence staining of the chick visual system with the 6D2 antibody. At E3 (a), all basal laminae are labeled $(L$, lens). At E8 $(b)$, both the retinal optic fiber layer $(R F L)$ as well as the optic fiber layer $(O F L)$ and the tectobulbar tract (TBT) of the tectum opticum $(c)$ are stained. At E6 $(d)$, the $6 \mathrm{D} 2$ antigen is prominent in the optic nerve $(O N)$ from the retina to the chiasm $(\mathrm{CH})$. At $\mathrm{E} 12(e)$, the antigen is only present in basal lamina structures of the optic nerve and is absent in nerve fibers. The distribution of the $6 \mathrm{D} 2$ antigen is identical to that of the $3 \mathrm{~A} 12$ proteoglycan. Scale bar: $250 \mu \mathrm{m}$ for $a$, $d$, and $e ; 100 \mu \mathrm{m}$ for $b$ and $c$.

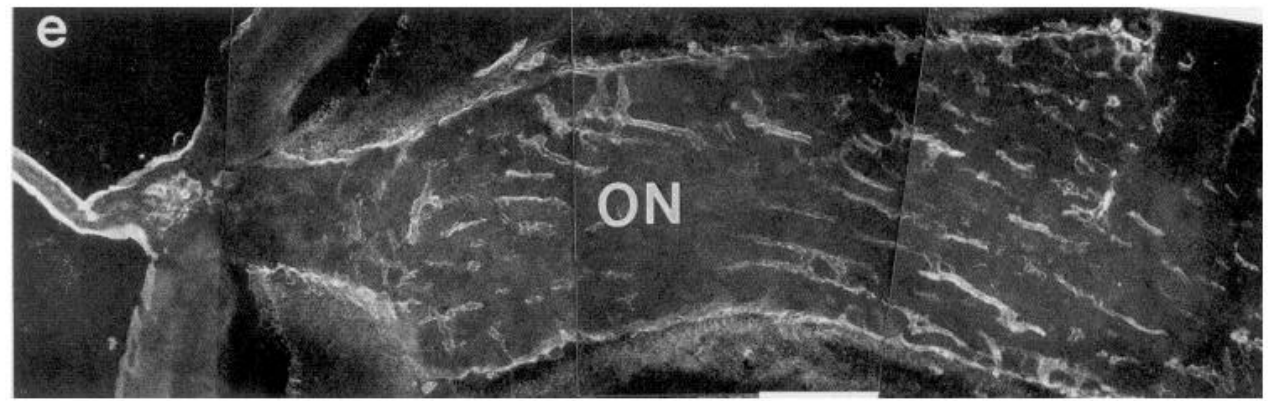

to the arrival of axons, and present in the cell-free vitreous body. The presence of the proteoglycan in the basal lamina and vitreous body further suggests that it is not an integral membrane proteoglycan, but a member of the extracellular matrix proteins. Its localization on the outer surface of optic axons in vivo, but not in vitro, suggests that the proteoglycan is secreted and bound onto the axonal surface by heparan sulfate proteoglycan-binding proteins with intermediate to low binding affinity.

Detailed studies on the visual system showed that the expression of the heparan sulfate proteoglycan in the optic pathways is developmentally regulated. The proteoglycan exists in the pathway only at a time when axons were growing and disappears by the time the optic fibers have reached their target around E10 (Goldberg, 1974). This temporal regulation applied also for other areas of the CNS. The transient appearance of the protein in developing fiber tracts suggests that the protein is involved in some aspect of neurite outgrowth. Preliminary studies have shown that the isolated proteoglycan supported the outgrowth of axons from dorsal root ganglia but not from retina explants. The presence of several unidentified proteins that copurified with the proteoglycan, however, does not allow a straight conclusion of whether or not the proteoglycan is supportive for neurite outgrowth.

It is well documented that heparan sulfate proteoglycan can bind a number of growth factors and adhesion proteins. The binding of FGF by heparan sulfate proteoglycan (reviewed by Klagsbrun, 1990) may provide a means to store and protect FGF in the basal lamina matrix from proteolytic degradation (Vlodavsky et al., 1987; Saksela et al., 1988; Klagsbrun, 1990). The existence of a heparan sulfate proteoglycan in developing axonal tracts might therefore be important for binding trophic factors to growing nerve fibers. Heparan sulfate proteoglycan has also shown to be a binding partner for several adhesion proteins with heparin binding sites, such as N-CAM (Cole et al., 1986), fibronectin, laminin, and thrombospondin. Indeed, a complex of heparan sulfate proteoglycan with laminin and fibronectin could be demonstrated in vitreous body by showing that these proteins copurify with the proteoglycan. In vivo, the proteoglycan may help concentrate these neurite outgrowthpromoting proteins in the vicinity of nerve fibers to provide a better environment for neurite extension.

The distribution of the neuronal heparan sulfate proteoglycan 

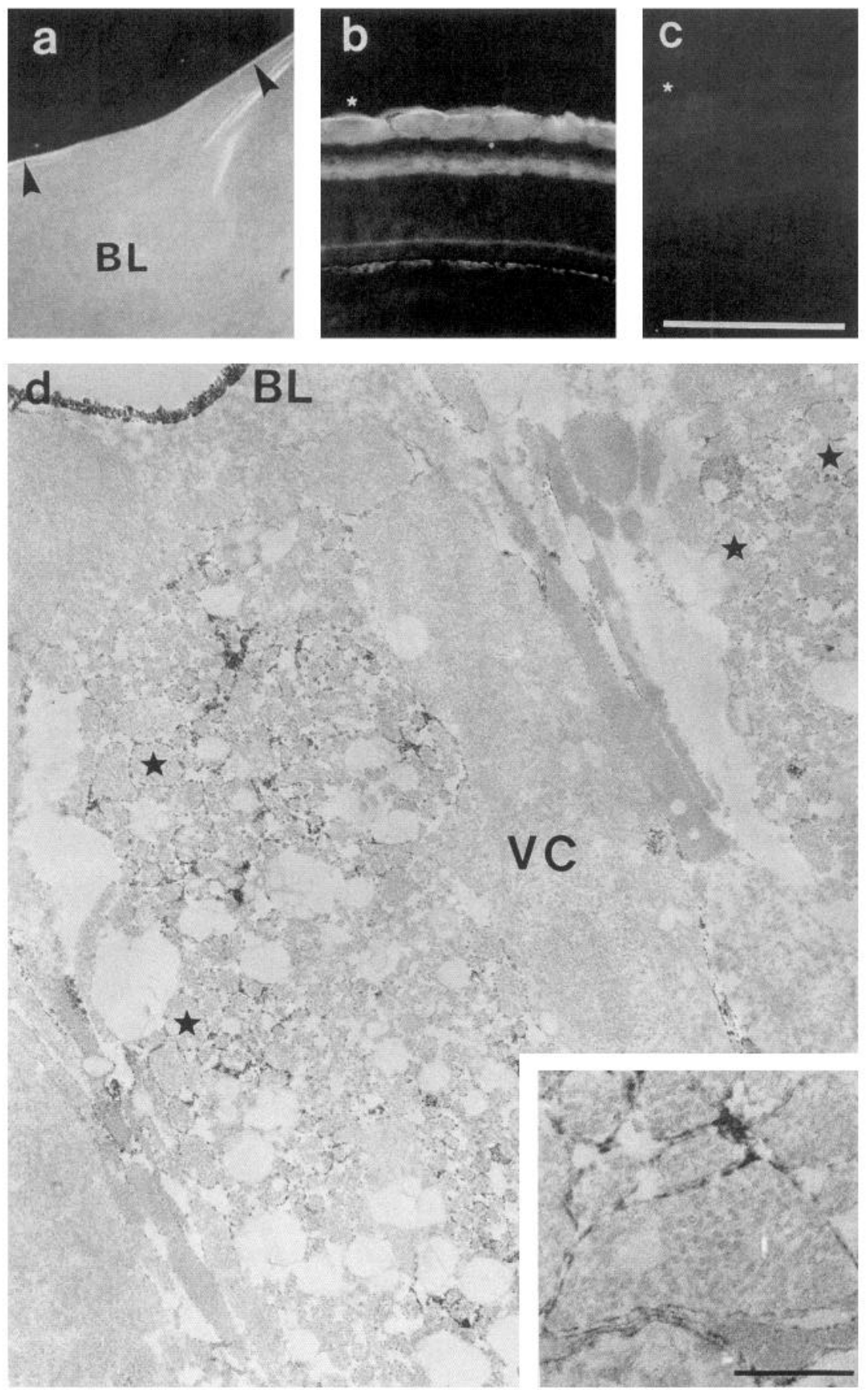

Figure 8. Localization of the neuronal heparan sulfate proteoglycan in a cellfree basal lamina whole-mount $(a)$ and in the optic fiber layer of an E8 eye injected with 6D2 ascites on E7 $(b-d)$. The strong staining of a whole-mounted retinal inner limiting membrane indicated that the neuronal heparan sulfate proteoglycan was present in the basal lamina. When the $6 \mathrm{D} 2$ antibody was injected in vivo, the distribution of the injected antibody was visualized by reacting the sections with a fluorescent secondary antibody $(b, c)$, or with a peroxidase-labeled antibody for ultrastructural studies $(d)$. The injected retina showed a strong labeling in the inner limiting membrane (star between bars), the optic fiber layer, and the inner plexiform layer $(b)$. The contralateral retina showed no labeling at all (c); the position of the basal lamina (star between bars) is indicated. At the electron microscopic level $(d)$, the heparan sulfate proteoglycan was detected in the retinal basal lamina $(B L)$ and in the optic fiber layer decorating the surface of the individual axons (stars; $V C$, ventricular cells). The inset shows labeled axons at higher magnification. Scale bars: $a-c$, $250 \mu \mathrm{m} ; d, 1 \mu \mathrm{m} ;$ inset, $0.25 \mu \mathrm{m}$.

was compared with the distribution of heparan sulfate proteoglycans derived from muscle basal laminae or EHS mouse tumor (perlecan). Despite their presence in basal laminae, the distribution of perlecan and the neuronal heparan sulfate proteoglycan in the basal laminae was almost complementary. For example, perlecan was prominent in lens and muscle, where the neuronal heparan sulfate proteoglycan was almost absent. The opposite relationship was found for the inner limiting membrane of the retina, where the neuronal heparan sulfate proteoglycan was prominent and perlecan scarce. The different staining patterns demonstrate that more than one heparan sulfate proteoglycan exists in the extracellular matrix of embryos. The diversity of heparan sulfate proteoglycans is highlighted by the fact that a large number of heparan sulfate proteoglycans have been identified from various tissues, such as kidney glomeruli (Kanwar et al., 1984; Olgemoeller et al., 1989), liver sinusoids (Soroka and Farquhar, 1991), brain (Matthew et al., 1985; Dow et al., 1991), EHS tumor (Hassel et al., 1980; Vigny et al., 1988; Noonan et al., 1991), and endothelial cells (Buonassi and Colburn, 1983; Kojima et al., 1992). While most of the proteoglycans have a similar molecular weight, around $400-600 \mathrm{kDa}$, the size of their core proteins varies from 25 to $500 \mathrm{kDa}$. Biochemical comparisons of the $3 \mathrm{~A} 12 / 6 \mathrm{D} 2 / 3 \mathrm{~A} 3 / 9 \mathrm{E} 10$ antigen with other heparan sulfate proteoglycans did not show any similarity between them. For example, the heparan sulfate proteoglycans previously isolated from brain tissue have core proteins that are 

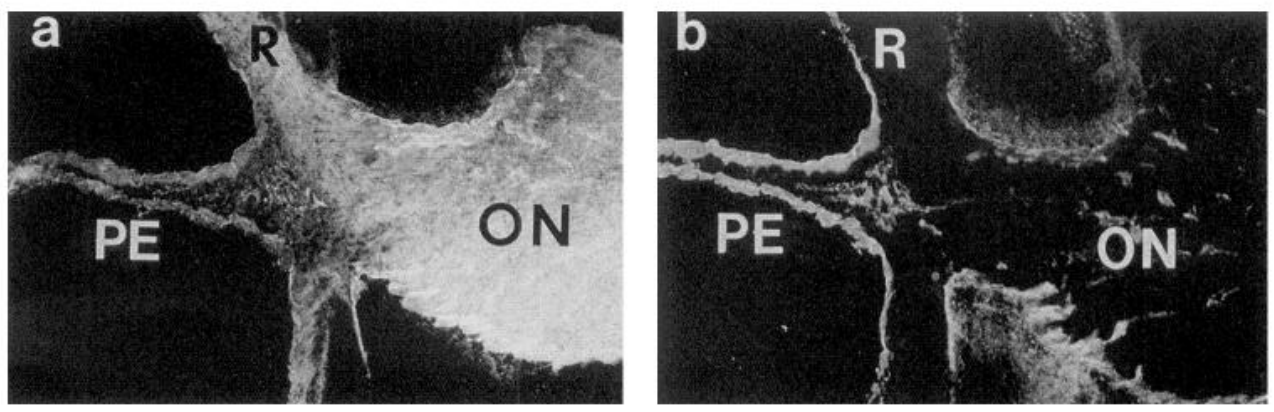

Figure 9. Immunofluorescence micrographs showing the distribution of the neuronal heparan sulfate proteoglycan $(a, c, e)$ and the muscle-derived heparan sulfate proteoglycan (clone $33-2$ ) $(b, d, f)$ in brain and muscle. At E8 $(a$, $c$ ), the neuronal heparan sulfate proteoglycan was present in basal laminae, in the optic nerve ( $a ; O N$, optic nerve; $P E$, pecten), and in various layers of the tectum opticum $(c)$. In adjacent sections, antibodies to the muscle-derived proteoglycan labeled the basal laminae $(b)$ and the pia $(d ; P$, pia), but not the optic nerve $(b)$ or the parenchyma of the brain $(d)$. By E10 $(e, f)$, some labeling of the neuronal heparan sulfate proteoglycan was detected in muscle ( $e ; M$, muscle); however, the most prominently stained structures were the nerves $(N)$ serving the muscle. The muscular heparan sulfate proteoglycan was abundant in muscle basal laminae but absent from the nerves $(f)$. Scale bar, $250 \mu \mathrm{m}$.
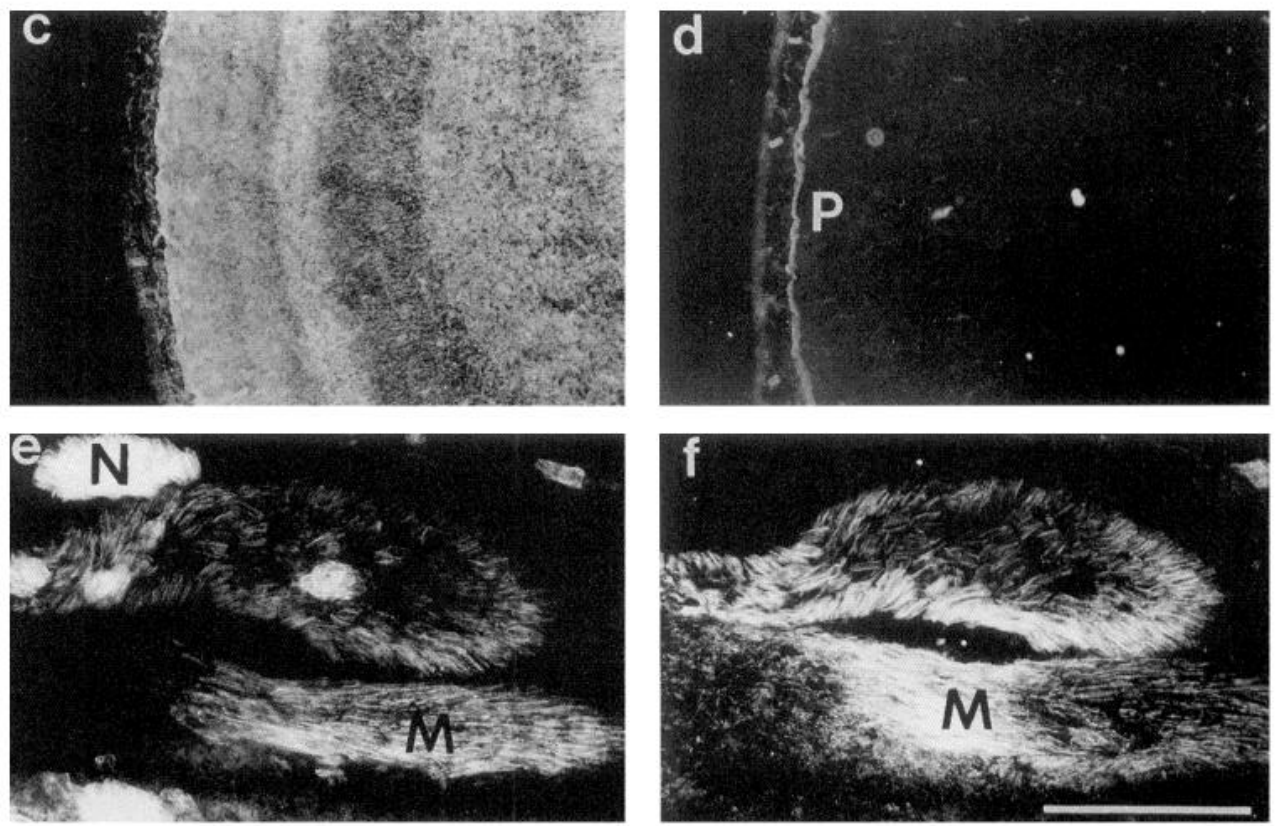

smaller than the 3A12/6D2 core protein (Matthew et al., 1985; Dow et al., 1988). This includes the INO antigen, whose heparan sulfate proteoglycan has a molecular weight of about $150 \mathrm{kDa}$ (Bronner-Fraser and Lallier, 1988).

The present data demonstrate the presence of a novel type of heparan sulfate proteoglycan in the developing nerve fiber layers. While the localization in axonal tracts suggests that the proteoglycan is involved in some aspect of neurite outgrowth, further studies are necessary to clarify its biological role in vivo.

\section{References}

Anderson H, Tucker RP (1989) Spatial and temporal variation in the structure of the basal lamina in embryonic grasshopper limbs during pioneer neurone outgrowth. Development 106:185-194.

Baron-van Evercooren A, Kleinman HK, Ohno S, Marangos P, Schwartz JP, Dubois-Dalq ME (1984) Nerve growth factor (NGF), laminin (LN) and fibronectin (FN) promote neurite growth in human fetal sensory ganglia cultures. J Cell Biol 5:133a.

Bayne E, Anderson M, Fambrough D (1984) Extracellular matrix organization in developing muscle: correlation with acetylcholine receptor aggregates. J Cell Biol 99:1486-1501.

Brittis P, Cannings D, Silver J (1992) Chondroitin sulfate as a regulator of neuronal patterning in the retina. Science 225:733-736.

Bronner-Fraser M, Lallier T (1988) A monoclonal antibody against a laminin-heparan sulfate proteoglycan complex perturbs cranial neural crest migration in vivo. J Cell Biol 106:1321-1329.

Buonassi V, Colburn P (1983) Antibodies to the heparan sulfate proteoglycans synthesized by endothelial cell cultures. Biophys Biochem Acta 760:1-12.
Carbonetto S (1984) The extracellular matrix of the nervous system. Trends Neurosci 7:381-387.

Chiquet M, Fambrough D (1984) Chick myotendenous antigen. A monoclonal antibody as a marker for tendon and muscle morphogenesis. J Cell Biol 98:1926-1936.

Chiu A, Matthew W, Patterson P (1986) A monoclonal antibody that blocks the activity of a neurite regeneration-promoting factor: studies on the binding site and its localization in vivo. J Cell Biol 103:13861398.

Cohen J, Burne JF, McKinley C, Winter J (1987) The role of laminin and the laminin/fibronectin receptor complex in the outgrowth of retinal ganglion cell axons. Dev Biol 122:407-418.

Cole G, McCabe C (1991) Identification of a developmentally regulated keratan sulfate proteoglycan that inhibits cell adhesion and neurite outgrowth. Neuron 7:1007-1018.

Cole G, Loewy A, Glaser L (1986) Neuronal cell-cell adhesion depends on interactions of N-CAM with heparin-like molecules. Nature 320: 445-447.

Condic ML, Bentley D (1989) Removal of the basal lamina in vivo reveals growth cone-basal lamina adhesive interactions and axons tension. J Neurosci 9:2678-2686.

Davies GE, Varon S, Engvall E, Manthorpe M (1985) Substratumbinding neurite-promoting factors: relationship to laminin. Trends Neurosci 8:528-532.

Davies GE, Blaker S, Engvall E, Varon S, Manthorpe M, Gage F (1987a) Human amnion basement membrane serves as a substratum for growing axons in vitro and in vivo. Science 236:1106-1109.

Davies GE, Engvall E, Varon S, Manthorpe M (1987b) Human amnion membrane as substratum for peripheral and central nervous system neurons. Dev Brain Res 33:1-10.

Dow K, Mirsky S, Roder J, Riopelle R (1988) Neuronal proteoglycans: biosynthesis and functional interaction with neurons in vitro. J Neurosci 8:3278-3289. 
Dow K, Riopelle R, Kisilewsky R (1991) Domains of neuronal heparan sulfate proteoglycan involved in neurite growth on laminin. Cell Tissue Res 265:345-351.

Fazekas S, de Groth S, Scheidegger D (1980) Production of monoclonal antibodies: strategy and tactics. J Immunol Methods 35:1-21.

Gallagher J (1989) The extended family of proteoglycans: social residents of the peripheral zone. Curr Opin Cell Biol 1:1201-1218.

Gallagher J, Lyon M, Stuart W (1986) Structure and function of heparan sulfate proteoglycan. Biochem J 236:313-326.

Goldberg S (1974) Studies on the mechanics of development of the visual pathways in the chick embryo. Dev Biol 36:24-43.

Halfter W (1989) Antibodies to basal lamina and glial endfeet disturb the normal extension of axons on retina and pigment epithelium basal laminae. Development 107:281-297.

Halfter W, Chen SF (1987) Immunohistochemical localization of laminin, neural cell adhesion molecule, collagen type IV and T-61 antigen in the embryonic retina of the Japanese quail by in vivo injection of antibodies. Cell Tissue Res 249:487-496.

Halfter W, von Boxberg Y (1992) Axonal growth on solubilized and reconstituted matrix from the embryonic chicken inner limiting membrane. Eur J Neurosci 4:840-852.

Halfter W, Reckhaus W, Kroeger S (1987) Nondirected axonal growth on basal lamina from avian embryonic neural retina. J Neurosci 7:3712-3722.

Hantaz-Ambroise D, Vigny M, Koenig J (1987) Heparan sulfate proteoglycan and laminin mediate two different types of neurite outgrowth. J Neurosci 7:2293-2304.

Hassel J, Robey P, Barrach H, Wilczek S, Rennard SJ, Martin G (1980) Isolation of a heparan sulfate-containing proteoglycan from basement membrane. Proc Natl Acad Sci USA 77:4494-4498.

Hassel J, Kimura J, Hascall V (1986) Proteoglycan core protein families. Annu Rev Biochem 55:539-567.

Hockfield S (1990) Proteoglycans in neural development. Semin Dev Biol 1:55-63.

Höök M, Kjellen L, Johannsson S, Robinson J (1984) Cell-surface glycosaminoglycans. Annu Rev Biochem 53:847-869.

Hopkins JM, Ford-Holevinski TS, McCoy JP, Agranoff BW (1985) Laminin and optic nerve regeneration in the goldfish. J Neurosci 5:3030-3038.

Hynes R, Lander A (1992) Contact and adhesive specificities in the associations, migrations and targeting of cells and axons. Cell 68:303322.

Kanwar Y, Veis A, Kimura J, Jakubowsky M (1984) Characterization of heparan sulfate proteoglycan of glomerular basement membrane. Proc Natl Acad Sci USA 81:762-766.

Kearney JF, Radbruch A, Liesegang B, Rajewsky K (1979) A mouse myeloma cell line that has lost immunoglobulin expression but permits the construction of antibody-secreting hybridoma cell lines. $J$ Immunol 123:1548-1558.

Klagsbrun M (1990) The affinity of fibroblast growth factors (FGFs) for heparin; FGF-heparan sulfate interactions in cell and extracellular matrix. Curr Opin Cell Biol 2:857-863.

Kojima T, Leone C, Marchildon G, Marcum J, Rosenberg R (1992) Isolation and charactcrization of heparan sulfatc protcoglycans produced by cloned rat microvascular cells. J Biol Chem 267:4859-4869.

Kroger S, Niehorster L (1990) Isolation, characterization, and substrate properties of the external limiting membrane from the avian embryonic optic tectum. J Neurosci Res 27:169-183.

Laemmli UK (1970) Cleavage of structural proteins during the assembly of the head of bacteriophage T4. Nature 227:680-685.

Lander AD, Fuji DK, Reichardt LF (1985) Laminin is associated with the "neurite outgrowth-promoting factors" found in conditioned media. Proc Natl Acad Sci USA 82:2183-2187.

Liesi P, Silver J (1989) Is astrocyte laminin involved in axon guidance in the mammalian CNS? Dev Biol 130:774-785.
Matthew W, Pattcrson P (1983) The production of a monoclonal antibody which blocks the action of a neurite outgrowth promoting factor. Cold Spring Harbor Symp Quant Biol 48:625-631.

Matthew W, Greenspan R, Lander A, Reichardt L (1985) Immunopurification and characterization of a neuronal heparan sulfate proteoglycan. J Neurosci 5:1842-1850.

McLoon SC, McLoon LK, Palm SL, Furcht LT (1988) Transient expression of laminin in the optic nerve of the developing rat. $J$ Neurosci 8:1981-1990.

Minamide LS, Bamburg JR (1990) A filter dye-binding assay for quantitative determination of protein without intereference from reducing agents and detergents. Anal Biochem 190:66-70.

Neugebauer K, Emmet C, Venstrom K, Reichardt L (1991) Vitronectin and thrombospondin promote retinal neurite outgrowth: developmental regulation and role of integrins. Neuron 6:345-358.

Noonan DM, Fulle A, Valente P, Cai S, Horigan E, Sasaki M, Yamada Y, Hassel JM (1991) The complete sequence of perlecan, a basement membrane heparan sulfate proteoglycan. J Biol Chem 266:2293922947.

Olgemoeller B, Schleicher E, Nehrlich A, Wagner E, Gerbiz K (1989) Isolation, characterization and immunological determination of basement membrane-associated heparan sulfate proteoglycan. Hoppe Seyler Z Biol Chem 370:1321-1329.

Rapraeger A, Jalkanen M, Bernfield M (1986) Cell surface proteoglycan associates with the cytoskeleton at the basolateral surface of mouse mammary epithelial cells. J Cell Biol 103:2683-2696.

Ruoslahti E (1989) Proteoglycans in cell regulation. J Biol Chem 264: 13369-13372.

Saksela O, Moscatelli D, Sommer A, Rifkin D (1988) Endothelial cellderived heparan sulfate binds basic fibroblast growth factor and protects it from proteolytic degradation. J Cell Biol 107:743-751.

Sanes JR (1989) Extracellular matrix molecules that influence neural development. Annu Rev Neurosci 12:491-516.

Smalheiser NR, Crain SM, Reid LM (1984) Laminin as a substrate for retinal axons in vitro. Dev Brain Res 12:136-140.

Snow D, Lemmon V, Carrino D, Caplan A, Silver J (1990) Sulfated proteoglycans in astroglial barriers inhibit neurite outgrowth in vitro. Exp Neurol 109:111-130.

Soroka C, Farquhar M (1991) Characterization of a novel heparan sulfate proteoglycan found in the extracellular matrix of liver sinusoids and basement membranes. J Cell Biol 113:1231-1241.

Towbin H, Staehlin T, Gordon J (1979) Electrophoretic transfer of proteins from polyacrylamide gels to nitrocellulose sheets: procedures and some applications. Proc Natl Acad Sci USA 76:4350-4354.

Verna J-M (1985) In vitro analysis of interactions between sensory neurons and skin: evidence for selective innervation of dermis and epidermis. J Embryol Exp Morphol 86:53-70.

Verna J-M, Fichard A, Saxod R (1989) Influence of glycosaminoglycans on neurite morphology and outgrowth patterns in vitro. Int $\mathrm{J}$ Dev Neurosci 7:389-399.

Vigny $M$, Ollier-Hartmann $M$, Lavigne $M$, Fayein $N$, Jeanny J, I aurent $M$, Courtois $Y$ (1988) Specific binding of basic fibroblast growth factor to basement membrane-like structures and to purified heparan sulfate proteoglycan of the EHS tumor. J Cell Physiol 137:321-328.

Vlodavsky I, Folkman I, Sullivan R, Fridman R, Ishai-Michaeli R, Sasse J, Klugsbrun M (1987) Endothelial cell-derived basic fibroblast growth factor: synthesis and deposition into subendothelial extracellular matrix. Proc Natl Acad Sci USA 84:2292-2296.

Wang L, Denburg J (1992) A role for proteoglycans in the guidance of a subset of pioneer axons in cultured embryos of the cockroach. Neuron 701-714.

Wehrle B, Chiquet M (1990) Tenascin is accumulated along developing peripheral nerves and allows neurite outgrowth in vitro. Development 110:401-415. 